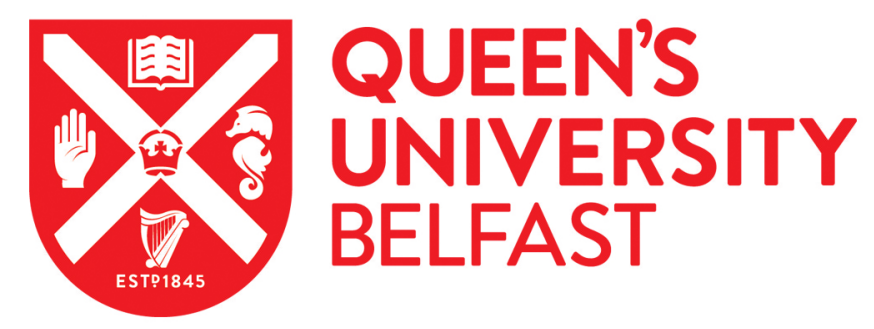

\title{
Flagging difference: Identification and emotional responses to national flags
}

Muldoon, O. T., Trew, K., Msetfi, R., \& Devine, P. (2020). Flagging difference: Identification and emotional responses to national flags. Journal of Applied Social Psychology. https://doi.org/10.1111/jasp.12657

\section{Published in:}

Journal of Applied Social Psychology

\section{Document Version:}

Peer reviewed version

Queen's University Belfast - Research Portal:

Link to publication record in Queen's University Belfast Research Portal

\section{Publisher rights}

(C) 2020 Wiley Periodicals, Inc.

This work is made available online in accordance with the publisher's policies. Please refer to any applicable terms of use of the publisher.

\section{General rights}

Copyright for the publications made accessible via the Queen's University Belfast Research Portal is retained by the author(s) and / or other copyright owners and it is a condition of accessing these publications that users recognise and abide by the legal requirements associated with these rights.

Take down policy

The Research Portal is Queen's institutional repository that provides access to Queen's research output. Every effort has been made to ensure that content in the Research Portal does not infringe any person's rights, or applicable UK laws. If you discover content in the Research Portal that you believe breaches copyright or violates any law, please contact openaccess@qub.ac.uk. 
Running Head: EMOTIONAL RESPONSES TO NATIONAL FLAGS

Flagging Difference: Identification and Emotional responses to National Flags

Orla Muldoon ${ }^{1}$, Karen Trew ${ }^{2}$, Rachel Msetfi ${ }^{1}$ and Paula Devine ${ }^{2}$

${ }^{1}$ University of Limerick

${ }^{2}$ Queen's University Belfast 


\begin{abstract}
Flags can be thought of as representations designed to unite the national community. Emotional responses are seen as being particularly important in driving allegiances to flags. In societies affected by conflict, where the nation itself is contested, emotional responses to national symbols however, have the potential to be divisive. In this study, using a large scale sample, emotions responses to the ingroup and outgroup flags and their relationship to national identities in Northern Ireland are considered. 1179 respondents reported their self-categorised national identity, as well as explicit emotional responses to both ingroup and outgroup flags. The strength of identification with preferred national group, British, Irish or Northern Irish, was also measured. Emotional responses to in-group flags were significantly related to both strength of national identification and the type of emotion, annoyed, hopeful, satisfied or uneasy, under consideration. Weaker emotional responses and different emotions were reported in response to out-group flags. The results of the study are interpreted as consistent with appraisal and intergroup emotions theory which suggests the strongest emotional responses are evidenced in response to symbols of one's own group. The importance of emotions to understanding the dynamics of intergroup conflict, and in Northern Ireland in particular, is also discussed.
\end{abstract}


Flagging Difference: Identification and Emotional responses to National Flags

National symbols can be viewed as conceptual representations of the imagined national community. Popular understandings of the role and use of flags often centre on their ability to strengthen allegiance to the nation (Billig, 1995) and is often marked by a strong emotional component (Feldman, Huddy \& Cassese, 2012). Given the diversity within any nation, however, these representations whilst clearly shared are amenable to multiple interpretations (Von Scheve, 2013). So representations are only emblematic of the general concept of a particular nation and can be seen to embody multiple ideals, histories and memories and are therefore likely to evoke a range of positive and negative emotional responses beyond patriotism or civic pride. To date, many of the studies that have explored the consequences of exposure to national flags have done so in contexts where national identity is uncontested and therefore these symbols have broadly positive connotations (Cram, Patrikios \& Mitchell, 2011). In this paper we take advantage of the Northern Irish context where issues of nation are contested. Our goal is to examine how peoples own national identity preferences impact on positive and negative emotional responses to flags associated with the national groups associated with the conflict.

\section{National Symbols as a window into Intergroup Relations}

The modern nation is not a fixed entity; rather it is reinvented and renewed in everyday ways. A key way in which the nation is embodied in everyday practice is through the use of emblems, most notably national flags (Billig, 1995), which are crucial to any nation state (Kemmelmeier \& Winter, 2008). Despite this, there is limited research examining the implications of exposure to flags (Butz, 2009) and the bulk of this research considers the impact of exposure on attitudes and cognitions (Butz, 2009; Kemmelmeier \& Winter, 2008) rather than on emotion or feelings. For example, in a series of three experiments, Hassin, Ferguson, Shidlovski and Gross (2007) found that subliminal exposure to the Israeli flag resulted in Israeli students shifting their political opinions. Participants exposed to the Israeli national flag endorsed more centrist political opinions. These findings can be seen as consistent with the position that flags can unite the national group (Chan, 2017; O'Donnell et al., 2016). Mirroring the power of the emblem to represent the richness and variability of large nation states, exposure to flags has been argued to results in 
greater group coherence (Callahan \& Ledgerwood, 2016; Hassin et al., 2007). For example recently Von Scheve et al. (2014) demonstrated that emotional engagement during a football tournament influenced group-related attitudes and solidarity beyond the tournament, which in turn subsequently enhanced the emotional significance attached to one's own national flag. In this way, the perceived emotional significance of national symbols can be seen as an important outcome of identity processes. It is for this reason that we consider emotional responses to flags, the main outcome variable in this paper, worthy of study.

\section{Group Based Emotion and National Identification}

Intergroup Emotions Theory (Smith, 1993) which seeks to understand the nature of emotions that arise from both group identification and group membership (Smith, Seger, \& Mackie, 2007), has been a key in the development of understanding group based emotions. Through the process of identification, events can become self-relevant and elicit group-based emotions (Smith, 1993). Smith and Lazarus (1993) argue that emotion experienced depends on the appraisal of motivational congruence (i.e. whether the situation helps or hinders group concerns). A situation that is seen to further the aims of one's own group is therefore likely to result in positive emotion, whereas one that impedes the aims of the ingroup is likely to result in negative emotion. Though the range of positive and negative emotions that can be experienced is wider ranging, previous research has typically used three to six positive or negative emotions as exemplars (Mackie, Devos, Smith, 2000; Smith et al., 2007). Here we used two positive and two negative emotions to ensure the positive and negative valence of emotions was considered.

When considering the issue of self-relevance of group emotions, intergroup emotion theory highlights two important factors: self-categorisation and level of identification (Iyer \& Leach, 2008). In order for any group situation to be selfrelevant, a respondent must categorise themselves as an ingroup member. There is some research suggests that simple categorical inclusion in an ingroup is sufficient to experience group-level emotions, as is the premise of intergroup emotions theory (Smith, 1993; Smith et al., 2007). Others argue that the level of ingroup identification (the psychological connection to a group) is also an important determinant. Mackie, Silver \& Smith (2004, p.231) contend that the higher the level of ingroup identification, the more "easily, frequently and intensely" group-based 
emotions are produced. Following from this, it is possible to predict that high identifiers should experience and express group emotions to a greater extent than low identifiers (Smith et al, 2007). Our study then examines both level of identification as well as self-categorisation in terms of national identity and how they relate to group based emotions.

Previously, Seger, Smith and Mackie (2009) used priming techniques (i.e. listening to music and viewing photographs) to induce social categorisation to demonstrate its impact on group-based emotions. This subtle activation produces group level emotions that are distinct from individual level emotions, that are socially shared, and that are also related to ingroup identification (Smith et al., 2007). In the majority of group-based emotion studies, participants are also asked to self-categorise as an ingroup member or level of identification is assessed in order to make a particular social identity salient. These lab based findings reveal strong, positive correlations between level of identification and positive emotions such as satisfaction, hopefulness, pride, and happiness. However, the correlations between level of identification and negative emotions such as fear, disgust, uneasiness, and irritation were more variable although they are generally negative and weak. Seger et al. (2009) speculate that different primes might produce different kinds of emotion profiles. The responses activated are potentially both positive and negative in situations of political violence where intergroup tensions remain high. And these intergroup dynamics are often built on national allegiances flags are likely to be particularly significant (Billig, 1995). For this reason we propose that emotional responses to national flags are a particularly rich avenue for real world research. They allow an ecologically valid approach to test some of the predictions of intergroup emotion theory. The present work therefore breaks new ground by considering the role of national self-categorisation and national identity strength on positive and negative emotional responses to national flags and symbols.

\section{Flags and National identities in Contested Contexts: The Case of} Northern Ireland

Flags are seen as important tools of national mobilisation not least because political leaders use patriotism and national allegiance to mobilise support for particular political positions (Becker et al., 2017; Reicher \& Hopkins, 2004) and the nation is routinely mobilised to achieve political aims and objectives. Callahan and 
Ledgerwood (2016) in a series of studies suggest that flags are particularly used strategically in threatening contexts to facilitate group solidarity. A key assumption of the historical conceptualisations of a nation state can be seen as cultural homogeneity (Schnapper 2002). However, modern nations are often multicultural and ethnically heterogeneous. As such problems can present with citizens having allegiance to multiple nations (e.g. Irish-American) within the same nation, or indeed if the nation itself is a site of contestation. In these situations, the nation must assert its own values and power with regard to other states, even within its own national boundaries (McGlynn, Tonge \& McAuley, 2014). In such instances, pithy symbols condense complicated and contradictory messages into a single unifying image: a low cost tool for popular political mobilisation (Billig, 1995).

In situations of political conflict where disputes around national identity can be as significant as the struggle over power and resources themselves (Kelman, 1969), these issue are writ large. National identity can be viewed as 'hot' (Billig, 1995) and national flags can be seen to be imbued with tremendous significance and meaning. And so it was that as Northern Ireland settled into an uneasy peace after the Belfast Good Friday Agreement (MacGinty, Muldoon \& Ferguson, 2007) flags have come to play a significant part in the maintenance of the conflict and are the source of ongoing controversy (Brown \& Macginty, 2003; Butz, 2009; Morris, 2005). Claims and displays of national identity are a key source of intergroup tensions (Stevenson \& Muldoon, 2010). The use of flags at commemorations have given rise to considerable violence in the last decade since the collection of this data in 2007- not least because flags remain important and relevant for everyday life in divided societies (Nolan \& Bryan, 2016).

Adding further, if welcomed, complexity to issues of national identity in Northern Ireland is the rise of a new national self-categorisation, namely 'Northern Irish' (Devine \& Schubotz, 2004). Northern Irish identity is a national selfcategorisation that emerged in the wake of the Agreement (Lowe \& Muldoon, 2014). In a recent paper, in three separate studies the rise of this Northern Irish national identity preference and it complex association with religious demography and social attitudes has been documented (Lowe \& Muldoon, 2014). Categorising as Northern Irish is associated with more inclusive social attitudes though it appears to have little impact on political preferences. However as yet there is no national flag associated with the Northern Irish identity, emerging as it did as a third national identity 
preference, from the ground up as it were. This means that responses to national flags necessarily pertain to those associated with Britishness and Irishness.

In Northern Ireland similar to other situations affected by long standing intergroup tensions (Kelman, 1999), patterns of identity tend to have particular characteristics. For example that national and religious identities tend to be conflated and overlap significantly, though not completely (see Muldoon et al., 2007 for a discussion of these issues). One cannot therefore assume that all Catholics are Irish or all Protestants, British. So for our purposes and to ensure correct alignment of allegiance to each flag, we assessed peoples emotional response to the two available national flags according to national group self categorisation.

\section{The Present Study}

Our review of the literature suggests that there are now three main national groups in Northern Ireland. The British group who remain the majority, are traditionally Protestant, and wish to maintain the union with Britain. The Irish group, largely Roman Catholic, wish to be reunited with the rest of the island of Ireland. And in more recent years a substantial minority of Northern Irish has emerged that includes both Protestant and Catholic (Lowe \& Muldoon, 2014). We presented our three national identity groups with images of the two available national flags: the flags of Britain and Ireland, the Union Jack and Tricolour respectively. And so for the present purposes, national self-categorisation and national identification are the identities relevant and salient to our national flag primes.

From our review, it is clear that intergroup emotions theory suggests that self categorisation and identification as a group member are essential to the expression of group based emotion. Also intergroup emotions theory predicts reactions to ingroup flags should be strongest because self-relevance is highest for ingroup stimuli. As stated previously, however identities in Northern Ireland can be seen as both oppositional and negatively interdependent, and definitions of the self that distance the 'the other' can also be important and relevant for group members (Reicher, 1996). So, whilst we hypothesise main and interaction effects such that the strongest emotions expressed will be in response to images of in group flags $\left(\mathrm{H}_{1}\right)$, amongst those who are most strongly identified with their own group $\left(\mathrm{H}_{2}\right)$. We also hypothesise that responses to flags of the outgroup will be characterised by more 
negative than positive emotions in comparison to the responses evident in relation to ingroup flags $\left(\mathrm{H}_{3}\right)$.

\section{Method}

\section{Design and analysis}

Because of our interest in national symbols and sentiments, here we used respondent's own stated national identity as a measured independent variable at three levels, British, Irish and Northern Irish. Two images presented to all participants were the British Union Jack and the Irish Tricolour, the respective flags of these two nations. We considered all participants responses to these images as a function of their self-categorised national identity and their strength of national identification. Emotional responses to these visual images were the dependent measure; measured at four levels (uneasy/hopeful/annoyed/satisfied) using the same four point scale. The order of presentation of the flags and the measures was randomised.

\section{Sampling and Participants}

This research was incorporated into the 2007 Northern Ireland Life and Times (NILT) Survey. This survey is an annual cross-sectional survey of householders in Northern Ireland and responses to flags was undertaken in this year only and has not been undertaken since this time. Flags have been an ongoing source of contention in Northern Ireland and so interest in these emotional responses remains live.

Participants were surveyed in their own homes; there was no compensation for participation. The survey used a two-stage random sampling technique. Firstly, the Land and Property Services Agency provides a comprehensive sampling frame of non-institutional addresses, but no information about the number of people living at an address. Secondly, at each selected address, interviewers listed all members of the household eligible for inclusion in the sample: that is, all persons aged 18 or over living at the address. From this listing of eligible adults, the interviewer's computer randomly selected one adult. This person, the selected respondent, completed all questions using Computer Assisted Personal Interviewing $\left(\mathrm{CAPI}^{\mathrm{TM}}\right)$. The respondent also filled in a short self-completion questionnaire.

A systematic random sample of addresses was selected from the Land and Property Services Agency list of private addresses. This is the most up-to-date listing of private households and is made available to the Northern Ireland Statistics 
and Research Agency for research purposes. People living in institutions (though not in private households in such institutions) are excluded. A total of $33 \%$ of those selected did not want to participate, $8 \%$ were not contactable, giving a final response rate of $61 \%$. Of the 1179 respondents who were asked to self-categorize their national identity, 1092 categorised themselves as British, Irish or Northern Irish, the remaining group largely being Polish, Chinese or other European. Of the final sample in our analysis, $40.7 \%$ described themselves as British $(n=460), 31.4 \%$ categorised themselves as Irish $(n=330)$ and $27.9 \%$ categorised themselves as Northern Irish $(\mathrm{n}=302)$. These self-categorised national identity preferences were used to drive our analysis.

Of the final sample, $48.9 \%$ of respondents were male and $51.1 \%$ female. 1,009 participants also indicated their religious affiliation as either Protestant $(n=$ $555)$ or Catholic $(n=454)$. Mean age of the sample was $48.6(\mathrm{SD}=18.3)$. For the British group 346 (89\%) were Protestant and 45 (11\%) reported they were Catholics, for the Irish group 276 (92\%) reported they were Catholic and 25 (8\%) Protestant. For the Northern Irish respondents, 144 (57\%) reported they were Protestant and 108 (43\%) Catholic. $10.9 \%$ of respondents said that they had no religion, and $3.5 \%$ said that they had a religion other than one of the two main religious traditions (Catholic/Protestant) in Northern Ireland.

\section{Procedure}

All information relating to national self-categorisation and identification was completed prior to presentation of visual images. The two flags were then presented as visual images to all participants. We used pictures of the British Union flag (also referred to as the 'Union Jack') and the Irish tricolour presented as full size images on a standard laptop computer display. Participants then indicated their emotional responses to each of the images.

\section{Measures}

National identity strength: Strength of self-categorised national identity was measured using Luhtanen and Crocker's (1992) Collective self-esteem (CSE) scale. Responses were given on a Likert scale from 1 to 5 with 5 indicating higher levels of identification. The reliability and validity of the scale is good. It has been widely used in Northern Ireland previously (e.g. Schmid \& Muldoon, 2015). Here overall 
reliability was .82 overall. The questions were phrased to relate to national identity reading for example "In general, I'm glad to be a member of the national group that I belong to".

Emotional Responses to Flags and Symbols: Using a wording outlined by Smith et al (2007), respondents were first asked explicitly about emotion attached to their preferred national group. This was achieved by respondents being asked to indicate whether they felt annoyed, hopeful, satisfied and/or uneasy about being a British/Irish/Northern Irish person in Northern Ireland. Response options offered were on a scale of 1 (not at all) to 3 (very). Respondents were then asked to look at each image and indicate how the image made them feel on the same four emotional dimensions: annoyed, hopeful, satisfied and/or uneasy. We chose these four items with due attention to the safety of field workers and the political climate of the time, from the longer list employed in previous research (Smith et al., 2007). These four items ensured we had coverage of positively and negatively valenced items.

Respondents indicated their responses again using a three point scale where 3 was, for example, 'very annoyed', 2 was 'a bit annoyed', and 1 was 'not at all annoyed'

\section{Results}

\section{Approach to Analysis}

We analysed our data using both correlational analysis and moderated regression analysis. Strength of identification was examined in relation to explicit emotion using bivariate correlations as well as partial correlations where appropriate to examine the stability of any relationships within each national group (British, Irish, and Northern Irish). Emotional responses, three point Likert responses, were treated as a scale variable and therefore can be subjected to correlation and regression (Streiner \& Norman, 2008). We coded self-categorised national identity into two dummy variables. British was the reference category, the first dummy variable represented Irishness, the second Northern Irishness. Using PROCESS (Hayes, 2013), we then conducted moderated mediation analysis using model 1 to test the main and interaction effects of strength of national identity and national selfcategorisation on each emotional response to each flag (see Table 1 and 2). To facilitate understanding of any effects, we also used PROCESS to estimate the conditional means of our moderator, for those with high (1 standard deviation above 
the mean), medium (within one standard deviation of the mean) and low (1 standard deviation below the mean) national identity strength (see Table 3 and Figures 1 and 2).

\section{Feelings towards Flags: Strength of Identification and National Identity}

$\mathrm{H}_{2}$ states that strength of identification would be related to feelings experienced in response to presentation of British and Irish national flags. Partial correlations indicated support for this hypothesis. Controlling for participants' national group preference, strength of identification was related to both feelings of satisfaction, $r(751)=.12, p=.002$, and feelings of hopefulness in response to the Union Jack, $r(751)=.09, p=.020$, and Irish tricolour, $r(751)=.16, p<.001$ and feelings of annoyance in response to the Irish Tricolour, $r(751)=.08, p=.023$. Strength of identification was not related to reported uneasiness in response to either flag and no other significant relationships were observed.

\section{The Union Jack}

Our moderated regression analysis indicated identity strength, interacted with national identity preference to predict feelings of hopefulness and satisfaction in response to the Union Jack flag (see Table 1). These effects are illustrated in Figure 1. Feelings of hope and satisfaction in response to the Union Jack were seen to be conditional on preferred national identity at low $\left(F_{\text {hope }}(2,1055),=30.03, p<.001\right.$; $\left.F_{\text {sat }}(2,1059),=43.67, p<.001\right)$, medium $\left(F_{\text {hope }}(2,1055),=100.59, \mathrm{p}<.001 ; F_{\text {sat }}(2\right.$, $1059),=134.65, p<.001)$ and high $\left(F_{\text {hope }}(2,1055),=117.23, \mathrm{p}<.001 ; F_{\text {sat }}(2,1059)\right.$, $=121.11, p<.001)$ values of identity strength. Identity strength also had a main effect on feelings of satisfaction ( $b=-.16,95 \%$ CL $[.05-.22,-.10])$ and hopefulness $(b=-.19$, $95 \%$ CL $[-.25,-.13])$, but these effects are best understood in the context of the interactions outlined above.

From Figure 1, it can be seen that more highly identified British and Northern Irish responders report more hope and satisfaction in response to the Union Jack than those less strongly identified with their preferred national group. On the other hand, those who categorise as Irish, irrespective of their strength of identification, report little variability in their levels of satisfaction and hope when they view the Union Jack. Those who saw themselves as Irish also reported more 
annoyance in response to this image ( $b=-0.53,95 \%$ CL $[-.82,-.25]$ see Table 3$)$. National identity preference or strength did not predict uneasiness in response to presentation of the Union Jack (see Table 1,3) and no other effects were observed.

\section{The Irish Tricolour}

Our moderated regression analysis indicated that national identity preference and strength again interacted to predict responses to the Irish tricolour. Identity strength, as well as having a main effect on feelings of uneasiness $(b=-.07,95 \% \mathrm{CL}[-$ $.12,-.02])$ and annoyance $(b=-.10,95 \%$ CL $[-.14,-.05])$, interacted with national identity preference, as per $\mathrm{H}_{3}$, to predicted feelings of uneasiness $(b=.11,95 \% \mathrm{CL}$ $[.03, .20])$ and annoyance $(b=.13,95 \%$ CL $[.06, .21])$ in response to the Tricolour (see Table 2). In Figure 2, again using those who were high, medium and low in identity strength for illustrative purposes, it can be seen that more highly identified British and Northern Irish responders report more uneasiness and annoyance in response to the Irish Tricolour. Those who categorise as Irish report little difference in their levels of annoyance and uneasiness contingent on their strength of identity when presented with the Irish Tricolour. As such, feelings of uneasiness and annoyance were conditional on preferred national identity at low $\left(F_{\text {annoy }}(2,1063)\right.$, $\left.=14.18, p<.001 ; F_{\text {uneasy }}(2,1062),=17.58, p<.001\right)$, medium $\left(F_{\text {annoy }}(2,1063),=57.31\right.$, $\left.\mathrm{p}<.001 ; F_{\text {uneasy }}(2,1062),=56.64, p<.001\right)$ and high $\left(F_{\text {annoy }}(2,1063),=56.691, \mathrm{p}<.001\right.$; $\left.F_{\text {uneasy }}(2,1055),=50.51, p<.001\right)$ values of identity strength.

Identity strength also interacted with national identity preference to predict feelings of hopefulness $(b=-.13,95 \% \mathrm{CL}[-.21,-.04])$ and satisfaction $(b=-.13,95 \%$ CL $[-.21,-.05])$ in response to the Tricolour flag. The estimated conditional means for low (1 SD below the mean) medium (within $1 \mathrm{SD}$ of the mean) and high (1 SD above the mean) identity strength for each level of the moderator variable (British, Irish and Northern Irish) are presented in Table 2. Feelings of hope and satisfaction were conditional on preferred national identity at low $\left(F_{\text {hope }}(2,1058),=19.96\right.$, $\left.p<.001 ; F_{\text {sat }}(2,1055),=23.93, p<.001\right)$, medium $\left(F_{\text {hope }}(2,1058),=82.32, \mathrm{p}<.001\right.$; $\left.F_{\text {sat }}(2,1055),=93.33, p<.001\right)$ and high $\left(F_{\text {hope }}(2,1063),=80.72, \mathrm{p}<.001 ; F_{\text {sat }}(2\right.$, $1055),=88.79, p<.001)$ values of identity strength. Irish identifiers showed more positive responses to this flag in comparison to British and Northern Irish responders (see means Table 3). 


\section{Discussion}

We had three hypotheses that we examined using our data. First and in line with intergroup emotions theory, we hypothesised that the strongest emotions expressed will be in response to images of one's own group symbols and flags. We found support for this hypothesis. British identifiers reported the highest levels of hopefulness and satisfaction in response to images of the Union Jack and similarly Irish identifiers reported the highest level of hope and satisfaction in response to images of the Irish Tricolour. Though British identifiers had the strongest positive reaction to the Union Jack they also had the strongest negative responses to the Irish Tricolour, reporting higher levels of uneasiness and annoyance than either Northern Irish or Irish identifiers. Similarly, Irish identifiers reported significantly more annoyance in response to the Union Jack than either of the other two national groups. Overall, greater intensity of emotions on both the positive and negative dimensions of emotions was elicited from high identifiers as compared to low identifiers. These findings provide support for intergroup emotions theory which suggests that emotional responses to flags and symbols will be strongest where they have selfrelevance.

We also hypothesised that responses to flags would be strongest amongst those who are most strongly identified and that national self-categorisation and identification would interact to predict strength of emotional responses. In our study identity strength was a particular strong determinant of hope and satisfaction in response to the Union Jack and uneasiness and annoyance in response to the Irish Tricolour. In all of these cases strength of identity interacted with national identity self-categorisation, as hypothesised, to effect emotional responses with highly identified British responders showing the strongest emotional responses. Previous work has found weak and inconsistent relationships between identification and negative emotions towards one's own flag (Smith et al., 2007). This makes conceptual sense, high identifiers are likely to have positive rather than negative connotations of their own flags.

However in this study we also found high identifiers and more particularly highly identified majority group have more negative reactions to outgroup flags. This is an important finding and may have important applied value in contexts beyond 
Northern Ireland. Our pattern of findings amongst the British identifiers can be characterised as more negative than those evident in Irish or Northern Irish respondents. It is corroborated by other analysts of NILT who have evidenced increased nervousness amongst the British self categorisers in Northern Ireland (Devine \& Schubotz, 2004; MacGinty \& duToit). We believe this reflects the politics of the time and the changing status of the national groups within Ireland and the UK and vis-à-vis each other. It may also be linked to a sense that often arises in the aftermath of polarised conflict that there must be 'winners' and 'losers' (MacGinty \& duToit, 2007). Indeed the political climate that has accompanied a waning of privilege for one group over another Northern Ireland is a process that has resonance in many polarised contexts worldwide. Our findings suggest that where recession of privilege is perceived to occur, there is a need to guard against emotional responding from the majority group towards the outgroup in order to maintain good relations.

These findings are to our mind entirely consistent with appraisal theory of emotion including intergroup emotion theory (Smith et al., 1993). This theory of focuses on the centrality of appraisal to the particular emotions experienced. Similarly, theory (Haslam \& Reicher, 2006) and research (Muldoon et al., 2009; Schmid \& Muldoon, 2015) relating to the integrated social identity model of stress indicates that appraisal and adaptation to stressful and violent experiences are coloured by group membership and identification. The current findings add further weight to these positions, demonstrating not only that self-categorised group membership is related to emotion reported in response to symbols, but also that the level of identification with the group is also so related. Future research could usefully assess the inter-relations between emotion, psychological adaptation to stressful life events and social identification given the apparent paradoxical findings relating strength of identification to both greater emotionality and better psychological adaptation (Muldoon \& Lowe, 2012).

Our respondents reported feeling more than one emotion simultaneously in response to given images. Smith (1993) argues for the important of attending to the type of emotion evoked rather than focusing on a simple positive/negative dimension of affect. Here our analysis attending to four emotions separately certainly supports this. This again highlights the need to avoid focusing on a single or dichotomous positive and negative dimension of emotion in research studies. Given the difficult, 
contested and oppositional nature of identity relations in Northern Ireland, it is clear that both positive and negative emotions are expressed in response to flags. We believe that this is likely to be a particular issue in situations where existing divisions are live or as national identity is 'hot' (Billig, 1995). Consistent with Seger et al. (2009), we established a relationship between positive emotions and identification when identity was primed using group relevant images. However, our results call into question the value of a simple positive-negative dichotomy of emotions when considering group-based emotions. In effect, these findings extend the current literature by illustrating that specific symbols can have particular effects that go beyond the simplistic prediction that flags and positive images of the ingroup will prime positive emotion and negative images of the outgroup negative emotions. Future research should consider whether members of any one group have mixed, both positive and negative feelings, about their own or outgroup symbols and whether this is linked to socio-political polarisation.

The impetus for examining emotions in an intergroup context is the hypothesised link between emotion and action tendencies. The intention to act is based not only on what we think about the outgroup, but is also on feelings towards the outgroup and/or intergroup relations. Of course, this intention to act depends on the emotion evoked. Some emotions, such as anger at the outgroup, are particularly associated with action tendencies (Yzerbyt, Dumont,Wigdoldus, \& Gordijin, 2003); observers can feel angry towards an outgroup if the victims are member of the ingroup and the perpetrator a member of the outgroup. Clearly, findings such as this have particular resonance in Northern Ireland, where violence and victimization is often perceived as having this type of intergroup dynamic (Cairns \& Darby, 1998; Muldoon, McLaughlin, Trew, 2007). Equally, evidence suggests the role of sentiment and emotion as a driver of conflict and a barrier to peace (Halperin, 2011). According to Bar-Tal and Halperin (2011), where there is a history of political violence, group members can develop highly negative collective emotional orientations towards the outgroup. These emotions are often twinned with negative attitudes to the outgroup and appear to form a particularly noxious mix (Halperin, Russell, Dweck, \& Gross 2008) that can contribute to the maintenance of the conflict.

The success of this study in uncovering patterns of relations, points to the importance of conceptual clarity in the measurement of intergroup emotion. As 
outlined by Iyer and Leach (2008) the conflation of intragroup and intergroup emotions as well as those relating to the relations between groups has hampered progress in this area. Our findings suggest that the distinction between intra and intergroup emotions is an important one. Further, it suggests that emotion relating to the self as a group member (i.e. as the subject of the emotion) is readily primed using widely used symbols. Our findings represent an important ecologically valid addition to the literature in this area.

Whilst our ecologically valid approach offers insight into group based nature of emotion, it the approach comes with its own difficulties. Our groups did not always evidence clear patterns of findings. And despite a large sample size we could not explore the interaction of religious and national identity preferences due to small cell sizes in the more unusual religious/national alignments. Equally because of our large sample size our correlational data are sometimes significant when the extent of the relationships are modest. And whilst ecological validity was a goal, safety and risk were also of concern during the data collection phase of the research. As the study was undertaken in people's homes, it was critical for the safety of fieldworkers not to arouse particularly intense emotions in our respondents. Second, though we were interested in how particular emotions resulted from appraisal of flags, the emotions we assessed were limited to four, two positive and two negative. The inclusion of a wider array of such highly relevant emotions in the Northern Ireland context such as shame, anger or guilt was deemed to be too sensitive and potentially risky, even in a time of relative peace. Similarly, the presentation of computer images of flags rather than presenting actual folded flags was deemed necessary by the data collection agency- though the latter were likely to evoke far stronger emotional responses (von Scheve et al, 2014). Future research could also usefully extend our work to assess a wider array of emotions and the impact of multiple overlapping group memberships which was beyond the scope of the current study.

In conclusion, our findings demonstrating the emotions attached to national flags in Northern Ireland represent an important addition to the available research in this field. By adopting a framework of conceptual clarity in the operationalisation of group emotion we have been able to unpick the complexity of the specific relations between priming, strength of identification and emotional responding in a real world context. Our findings have moved the literature forward by demonstrating flags and 
symbols evoke patterns of negative and positive emotional responses in real world groups as opposed to lab settings. Further, we have added to literature in terms of demonstrating that these emotions can be manipulated by varying the symbols presented and that emotions evoked in response to flags are not unambiguously positive. In contested nations, flags can divide rather than unite.

\section{References}

Becker, J. C., Butz, D. A., Sibley, C. G., Barlow, F. K., Bitacola, L. M., Christ, O., Khan,S.S., Leong, C. Pehrson, S. .Srinivasan,N. Sulz, A., Tausch, N Urbanska, K \& Wright, S. C. (2017) What Do National Flags Stand for? An Exploration of Associations Across 11 Countries . Journal of cross-cultural Psychology, 48 (3), 335352. https://doi.org/10.1177/0022022116687851

Billig, M. (1995). Banal nationalism. London, Sage.

Brown, K., \& MacGinty, R. (2003). Public attitudes toward partisan and neutral symbols in post-agreement Northern Ireland. Identities: Global studies in culture and power, 10 (1), 83-108. https://doi.org/10.1177/0022022116687851

Bryan, D. (2015). Parades, flags, carnivals, and riots: Public space, contestation, and transformation in Northern Ireland. Peace and Conflict: Journal of Peace Psychology, 21(4), 565-573.

Butz, D. A. (2009). National symbols as agents of psychological and social change. Political Psychology, 30(5), 779-804. https://doi.org/10.1037/pac0000136

Cairns, E., \& Darby, J. (1998). The conflict in Northern Ireland: Causes, consequences and controls. American Psychologist, 53(7), 754-760. https://doi.org/10.1037/0003-066X.53.7.754

Callahan, S.P., \& Ledgerwood, A. (2016). On the psychological function of flags and logos: Group identity symbols increase perceived entity. Journal of Personality and Social Psychology, 110 (4), 428-550. https://doi.org/10.1037/pspi0000047

Chan, E. Y. (2017). Exposure to the American flag polarizes democratic republican ideologies. British Journal of Social Psychology, 56(4), 809-818.

Cram, L. Patrikios, S., \& Mitchell, J. (2011). What Does the European Union mean to its citizens? Implicit triggers, identity(ies) and attitudes to the European Union. Paper prepared for presentation at APSA Annual General Meeting, Seattle. 
Devine, P., \& Schubotz, D. (2004). Us and them? Institute of Governance Public Policy and Social Research, Queen's University Belfast .

Feldman, S., Huddy, L., \& Cassese, E. (2012). Emotional underpinnings of political behavior. Grounding Social Sciences in Cognitive Sciences, 125-156.

Halperin, E. (2011). Emotional barriers to peace: Emotions and public opinion of Jewish Israelis about the peace process in the Middle East. Peace and Conflict, 17(1), 22-45. https://doi.org/10.1080/10781919.2010.487862

Halperin, E., Russell, A. G., Dweck, C. S., \& Gross, J. J. (2011). Anger, hatred, and the quest for peace: Anger can be constructive in the absence of hatred. Journal of Conflict Resolution, 55(2), 274-291. https://doi.org/10.1177/0022002710383670

Hayes, A. F. (2013). Introduction to mediation, moderation, and conditional process analysis: A regression-based approach. New York, NY: Guilford Press.

Haslam, S.A., \& Reicher S. (2006). Stressing the group: Social Identity and the unfolding dynamics of responses to stress. Journal of Applied Psychology, 91(5), 1037-1052. https://doi.org/10.1037/0021-9010.91.5.1037

Hassin, R. R., Ferguson, M. J., Shidlovski, D., \& Gross, T. (2007). Subliminal exposure to national flags affects political thought and behavior. Proceedings of the National Academy of Sciences, 104(50), 19757-19761.

https://doi.org/10.1073/pnas.0704679104

Iyer, A., \& Leach, C.W. (2008). Emotion in inter-group relations. European Review of Social Psychology, 19, 86-125. https://doi.org/10.1080/10463280802079738

Kelman, H. C. (1999). The interdependence of Israeli and Palestinian national identities: The role of the other in existential conflicts. Journal of Social Issues, 55(3), $581-600$.

Kelman, H. C. (1969). Patterns of personal involvement in the national system: A social-psychological analysis of political legitimacy. In J. N. Rosenau (Ed.), International politics and foreign policy: A reader in research and theory (pp. 276288). New York: Free Press.

Kemmelmeier, M., \& Winter, D. G. (2008). Sowing patriotism, but reaping nationalism? Consequences of exposure to the American flag. Political Psychology, 29(6), 859-879. https://doi.org/10.1111/j.1467-9221.2008.00670.x

Lowe, R., \& Muldoon, O.T. (2014). Shared national identification in Northern 
Ireland: an application of psychological models of group inclusion post conflict . Group Processes and Intergroup Relations, 17(5), 602-616.

https://doi.org/10.1177/1368430214525808

Luhtanen, R., \& Crocker, J. (1992). A collective self-esteem scale: Selfevaluation of one's social identity. Personality and Social Psychology Bulletin, 18, 302-318. https://doi.org/10.1177/0146167292183006

Mackie, D. M., Devos, T., \& Smith, E. R. (2000). Intergroup emotions: explaining offensive action tendencies in an intergroup context. Journal of Personality and Social Psychology, 79(4), 602. https://doi.org/10.1037/00223514.79.4.602

Mackie, D.M., Silver, L.A., \& Smith, E.R. (2004). Intergroup emotions: Emotion as an intergroup phenomenon. In L.Z. Tiedens, \& C.W. Leach (Eds.). The social life of emotions (pp.227-245). New York: Cambridge University Press.

MacGinty, R., \& Du Toit, P. A. (2007) . Disparity of esteem: Relative group status in Northern Ireland after the Belfast Agreement. Political Psychology, 28, 1, 13-31.https://doi.org/10.1111/j.1467-9221.2007.00549.x

Mac Ginty, R., Muldoon, O. T., \& Ferguson, N. (2007). No war, no peace: Northern Ireland after the agreement. Political psychology, 28(1), 1-11.

McGlynn, C. Tonge, J., \& McAuley, J. (2014). The party politics of postdevolution identity in Northern Ireland. British Journal of Politics and International Relations, 16, 2, 273-290. https://doi.org/10.1111/j.1467-856X.2012.00528.x

McKay, S. (2000). Northern Protestants: An unsettled people. Belfast: Blackstaff Press.

Morris, E. (2005). Our own devices: National symbols and political conflict in the twentieth century Ireland. Dublin: Irish Academic Press.

Muldoon, O. T., \& Lowe, R. D. (2012). Social identity, groups, and posttraumatic stress disorder. Political Psychology, 33(2), 259-273. https://doi.org/10.1111/j.1467-9221.2012.00874.x

Muldoon, O.T., McLaughlin, K., \& Trew, K. (2007). Adolescents' perceptions of national identification and socialisation: A grounded analysis. British Journal of Developmental Psychology, 25(4), 579-594. https://doi.org/10.1348/026151006X173305 
Muldoon, O.T. Schmid, K. \& Downes, C. (2009). Political violence and psychological well- being: the role of social identity. Applied Psychology, 58(1), 129145. https://doi.org/10.1111/j.1464-0597.2008.00385.x

Muldoon, O.T., Trew, K., Todd, J. .,Rougier, N.,\& McLaughlin, K. (2007). Religious and national identity after the Belfast Good Friday agreement. Political Psychology, 28(1), 89-103. https://doi.org/10.1111/j.1467-9221.2007.00553.x

Nolan, P., \& Brien, D. (2016). Flags towards a new understanding, Institute of Irish Studies, Queen's University Belfast

O'Donnell, A. T., Muldoon, O. T., Blaylock, D. L., Stevenson, C., Bryan, D., Reicher, S. D., \& Pehrson, S. (2016). 'Something that unites us all': Understandings of St. Patrick's Day parades as representing the Irish national group. Journal of Community \& Applied Social Psychology, 26(1), 61-74. https://doi.org/10.1002/casp.2236

Reicher, S., \& Hopkins, N. (2000). Self and nation. Sage.

Schmid, K., \& Muldoon, O. T. (2015). Perceived threat, social identification, and psychological well--being: The effects of political conflict exposure. Political Psychology, 36(1), 75-92. https://doi.org/10.1111/pops.12073

Schnapper,D. (2002). Citizenship and national identity in Europe. Nations and Nationalism , 8(1), 1-14. https://doi.org/10.1111/1469-8219.00035

Seger, C.R., Smith, E.R., \& Mackie, D.M. (2009). Subtle activation of a social categorisation triggers group-level emotions. Journal of Experimental Social Psychology, 45(3), 460-467. https://doi.org/10.1016/j.jesp.2008.12.004

Smith, C.A. \& Lazarus, R.S. (1993). Appraisal components, core relational themes, and the emotions. Cognition and Emotion, 7(3), 233-269. https://doi.org/10.1080/02699939308409189

Smith, E.R. (1993). Social identity and social emotions: Toward new conceptualisations of prejudice. In D.M. Mackie \& D.L. Hamilton (Eds.). Affect, cognition and stereotyping: Interactive processes in group perception (pp.297-315). San Diego, CA: Academic Press. https://doi.org/10.1016/B978-0-08-088579-7.50017$\mathrm{X}$

Smith, E. R., Seger, C. R., \& Mackie, D. M. (2007). Can emotions be truly group level? Evidence regarding four conceptual criteria. Journal of Personality and Social Psychology, 93(3), 431. https://doi.org/10.1037/0022-3514.93.3.431 
Stevenson, C., \& Muldoon, O. T. (2010). Socio-political context and accounts of national identity in adolescence. British Journal of Social Psychology, 49(3), 583-599. https://doi.org/10.1348/014466609X475972

Streiner, D.L., \& Norman, G.R. (2008). Health measurement scales. A practical guide to their development and use (4th ed.). Oxford, Oxford University Press. https://doi.org/10.1093/acprof:oso/9780199231881.001.0001

Von Scheve, C. (2014). Interaction rituals with artificial companions: from media equation to emotional relationships. Science, Technology \& Innovation Studies, 10(1), 65-83.

Von Scheve, C., Beyer, M., Ismer, S., Kozłowska, M., \& Morawetz, C. (2014). Emotional entrainment, national symbols, and identification: A naturalistic study around the men's football World Cup. Current Sociology, 62(1), 3-23. https://doi.org/10.1177/0011392113507463

Yzerbyt, V., Dumont, M.,Wigdoldus, D. \& Gordijin, E. (2003). I feel for us: The impact of categorization and identification on emotions and action tendencies. British Journal of Social Psychology, 42, 4, 533-549. https://doi.org/10.1348/014466603322595266 
Table 1

Moderation effect of Self Categorised National identity on the relations between Strength of identification (EI) and feelings in response to the Union Jack (Uneasy, Annoyed, Satisfied and Hopeful), $N=112$

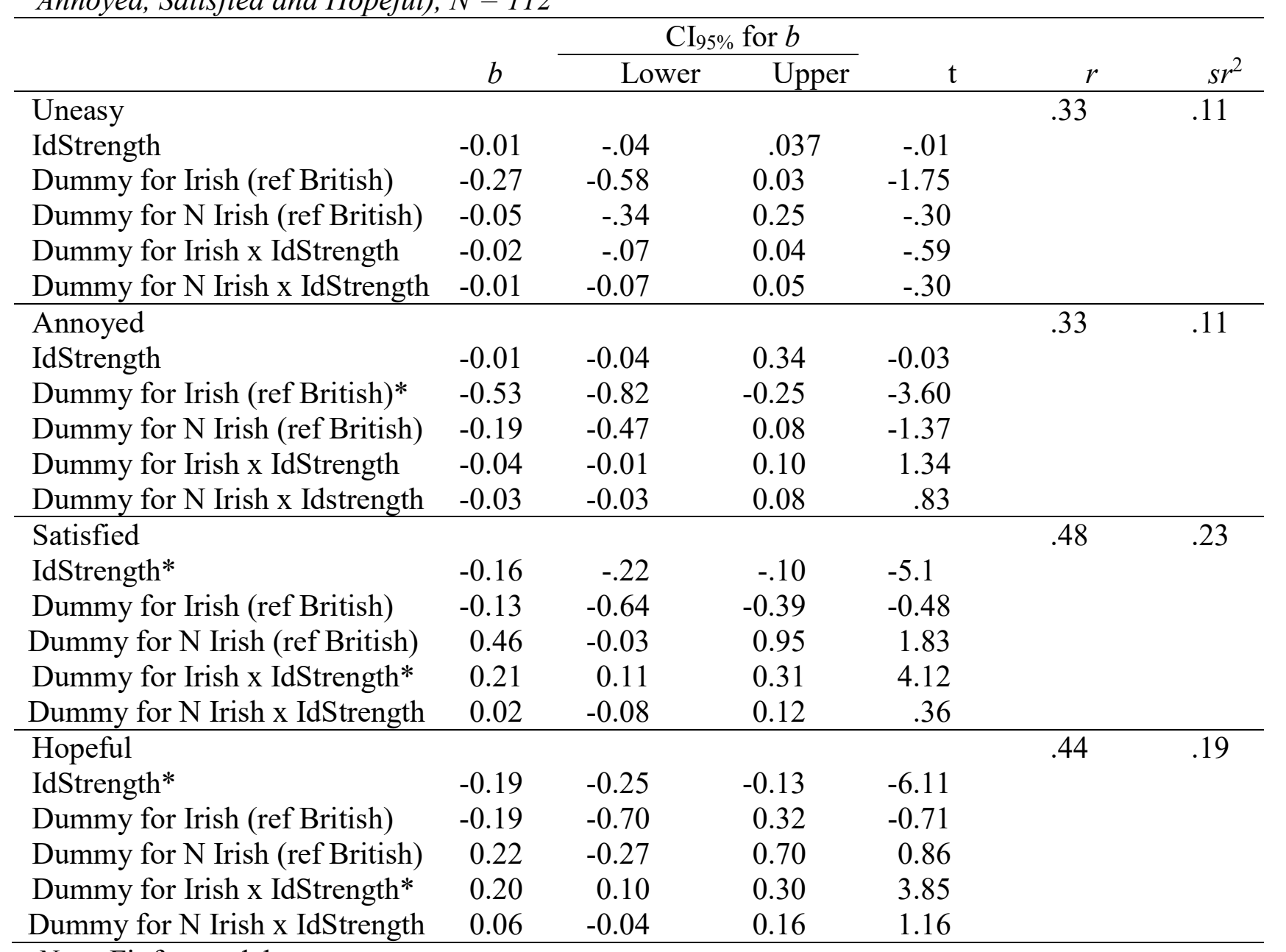

Note. Fit for model

Uneasy $R^{2}=11.11, F(5,1066)=26.65, p<.01$.

Annoyed $R^{2}=11.03, F(5,1062)=26.33, p<.01$.

Satisfied $R^{2}=23.42, F(5,1059)=64.79, p<.01$.

Hopeful: $R^{2}=18.72, F(5,1055)=48.59, p<.01$.

In all cases $*$ indicates $\mathrm{p}<.05$ 
Table 2

Moderation effect of Self Categorised National identity on the Relationship between Strength of identification (EI) and feelings in response to the Irish Tricolour (Uneasy, Annoyed, Satisfied and Hopeful)

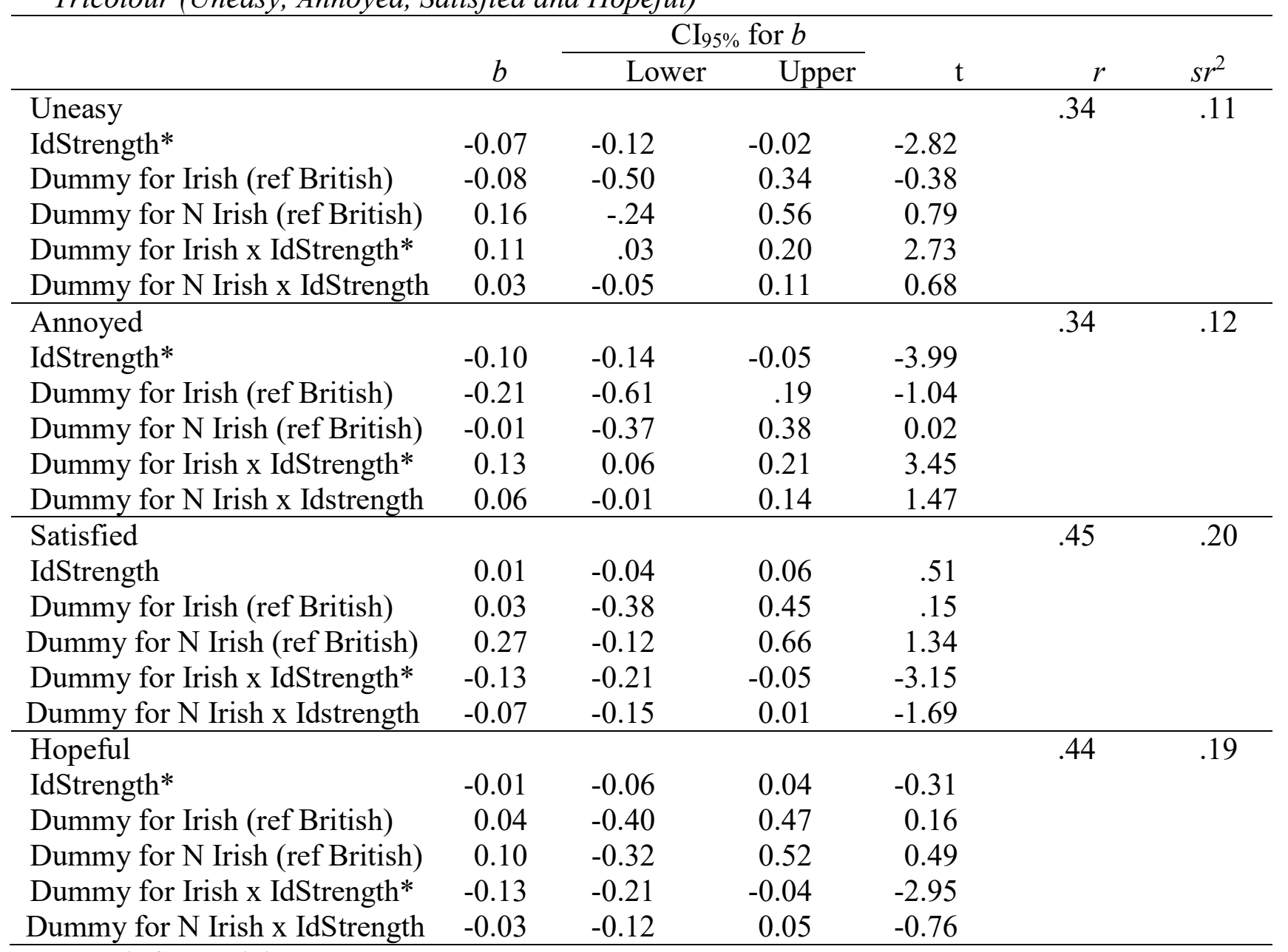

Note. Fit for model

Uneasy $R^{2}=11.25, F(5,1062)=26.91, p<.01$.

Annoyed $R^{2}=11.61 ;, F(5,1063)=27.92, p<.01$.

Satisfied $R^{2}=23.42, F(5,1059)=64.79, p<.01$.

Hopeful: $R^{2}=18.94, F(5,1058)=49.44, p<.01$.

In all cases $*$ indicates $\mathrm{p}<.05$ 
Table 3: Means reflecting high, medium and low national identity strength for British, Irish and Northern Irish identifiers.

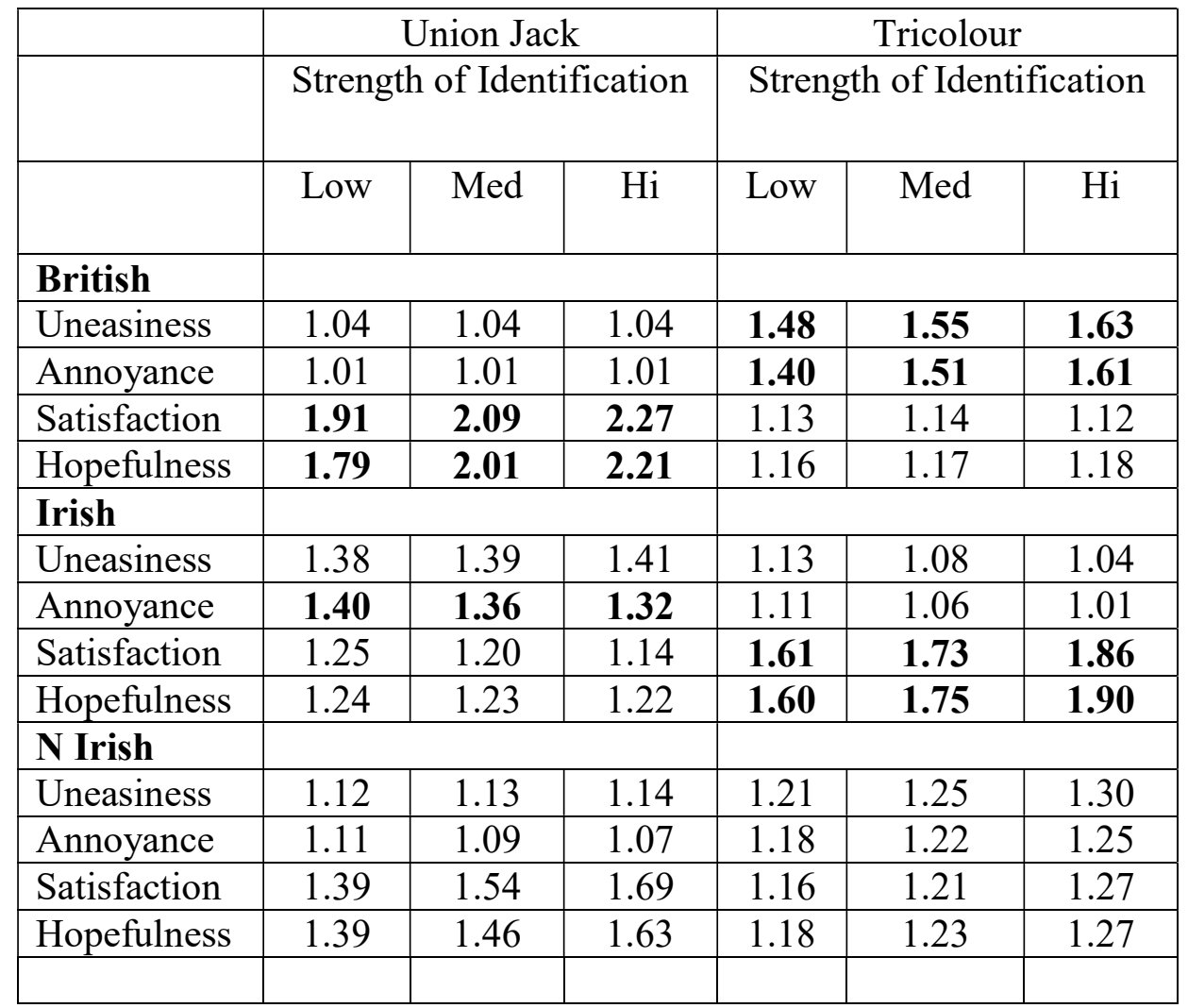

*Note: Significant differences conditional on identity strength within self-categorised national identity groups are indicated with bold. In all cases high represents a value of more than 1 standard deviation above the mean for national identity strength, medium is within one standard deviation and low is one standard deviation below mean national identity strength. 
Figure 1 Mean reported satisfaction and hopefulness in response to the Union Jack conditional on strength of national identity

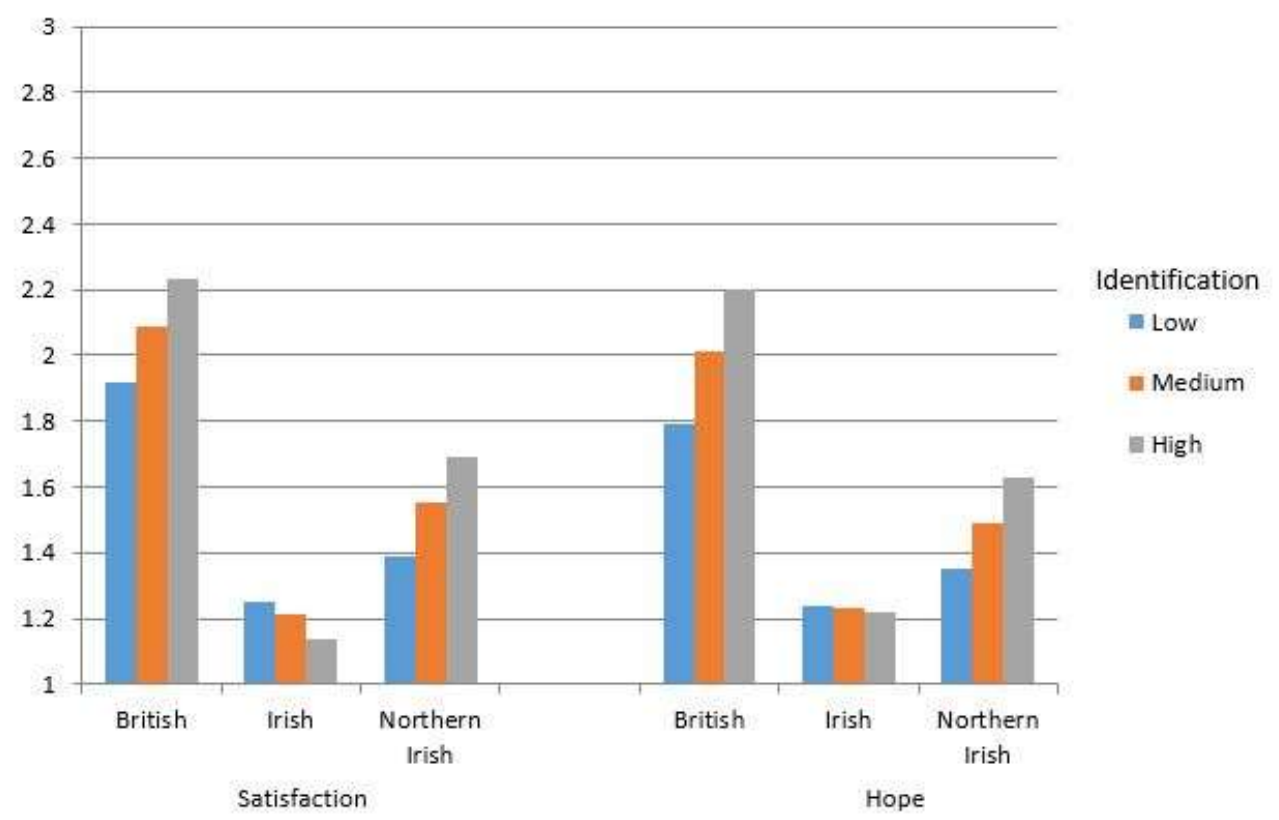


Figure 2 Mean reported uneasiness and annoyance in response to the Irish tricolor conditional on strength of national identity

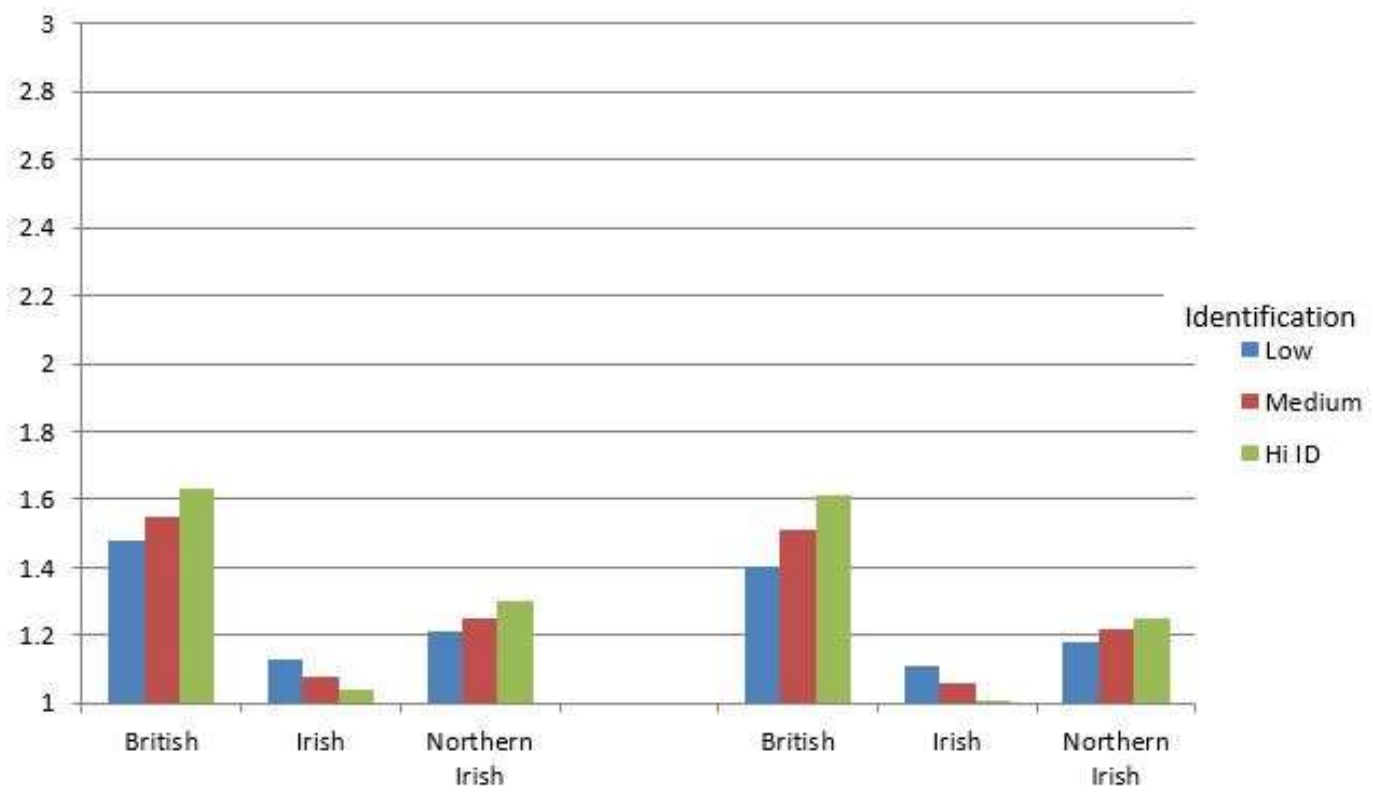

Uneasiness

Annoyance 